$\underline{\text { Рещензіï }}$

\title{
The new concept of biota protection oin the Republic of Moldova. The Red Data Book of Moldova (2015)
}

Cartea Roşie a Republicii Moldova. = The Red Book of the Republic of Moldova / Min. Mediului al Rep. Moldova, Acad. de Ştiinţe a Moldovei, Grădina Botanică \& Inst. de Zoologie; Comisia Naţ.: Valeriu Munteanu [et al.]; Col. de red.: Gheorghe Duca (preşedinte) [et al.]. - Ed. a 3-a. - Chişinău: Î.E.P. Ştiinţa, 2015 (Combinatul Poligr.). - 492 p.

In 2015, the Ministry of Environment, Academy of Sciences in the Republic of Moldova, Botanical Garden and Institute of Zoology, according to the national legal framework (The Environment Protection Act (1993), Law on State Protected Areas (1998), Law on the Red Book (2006), Law on the Plant World (2007), Law on Plant Communities (2007) etc.), the National Environmental Strategy for 2014-2023 (approved in 2014) and the Global Strategy for Plant Conservation 2011-2020, prepared and published the Red Book of the Republic of Moldova (the RBRM).

According to the Law of the Red Book, it should regulate nature protection activities, use and recovery of endangered, critically endangered, vulnerable, rare and not evaluated species of biota in order to prevent their disappearance and to ensure the conservation of genetic resources. This Law establishes the basic responsibilities of state structures at all levels, including scientific institutions of this field.

This edition of the Red Book is the third one after the issue of the first edition in 1978 (26 plant species and 29 species of vertebrates) and the second edition in 2001 (126 plant species and 116 animal species).

One volume of this edition of the RBRM includes plants, fungi and animals which require protection (while in Ukraine, for example, these groups of organisms are separated mainly due to the larger volume of material). The information about plants takes up almost a half of the book (plants and fungi are placed on pages 13-232, animals - on pages 234-469).

The RBRM provides information about 208 species of plants and fungi, 150 of which are angiosperms, 1 - gymnosperm, 14 - pteridophytes, 7 - bryophytes, 8 - algae, 14 basidiomycetes, 14 - ascomycetes, which constitutes 88 species more than in the second edition of the Red Book. The Book also includes 219 animals species, among which 30 are mammals, 62 - birds, 9 - reptilian, 9 - amphibian, 23 - fish, 1 - cyclostomatous, 80 - insects, 1 - colembols, 1 - crustaceans, 3 - bivalves, which is 103 species more than in the second edition. It is interesting that the RBRM lists both rare (Chrysopogon gryllus (L.) Trin., Colchicum triphyllum G. Kunze, Crambe tataria Sebeók, Eremogone cephalotes (M. Bieb.) Fenzl, Iris pontica Zapal., Gymnospermium odessanum (DC.) Takht., Schivereckia podolica (Besser) Andrz. ex DC., Scorzonera austriaca Willd., Securigera elegans Panč.) and common for Ukraine (Achillea ochroleuca Ehrh., Convolvulus lineathus L., Dianthus polymorphus M. Bieb., Ephedra distachya L., Jurinea stoechadifolia (M. Bieb.) DC., Nepeta parviflora M. Bieb., Pimpinella titanophila Woronow, Scorzonera mollis M. Bieb., Silene supina M. Bieb., etc.) species of plants. Some of the latter are weeds (Centaurea salonitana Vis., Erodium ciconium (L.) L.'Her).

The taxonomic groups of plants are arranged in the following order: flowering plants (Magnoliophyta: Magnoliopsida; Liliopsida), gymnosperms (Pinophyta), seedless vascular plants (Pteridophyta), bryophytes (Bryophyta), algae (Algae), fungi (Fungi: Basidiomycota; Ascomycota). In the RBRM, before each major group of plants at the rank of division, there is a list of taxa in Latin and Romanian with names of families. 


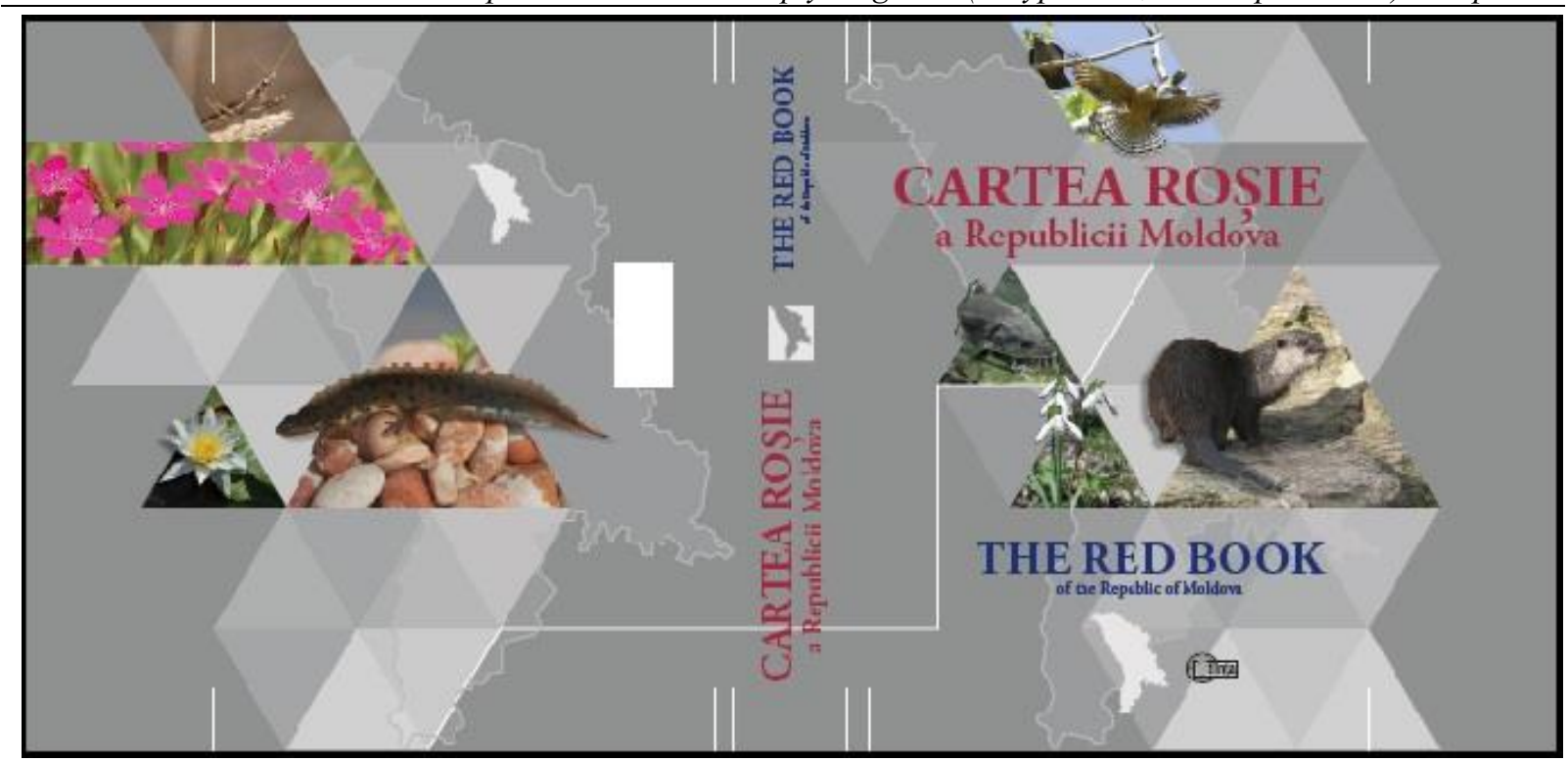

At the end of the RBRM there are indices of Latin and Moldavian (Romanian) names. The references (bibliography) are given by groups of organisms (separately for Magnoliophyta, Pinophyta, Pteridophyta, Bryphyta, Algae, Fungi).

Among seven IUCN categories in the Red Book of the Republic of Moldova only three (vulnerable (VU), endangered $(\mathrm{EN})$, critically endangered $(\mathrm{CR})$ ) are used, such categories as Extinct (EX) and Extinct in the wild (EW), and $\mathrm{T}=$ Near threatened (NT) are ignored.

Traditionally, in the Red Data Books of the countries in Eastern Europe, the data for each species are accompanied with a photo and a dot chart of localities with subdivision into current isolated places of registration and places of registration in the past.

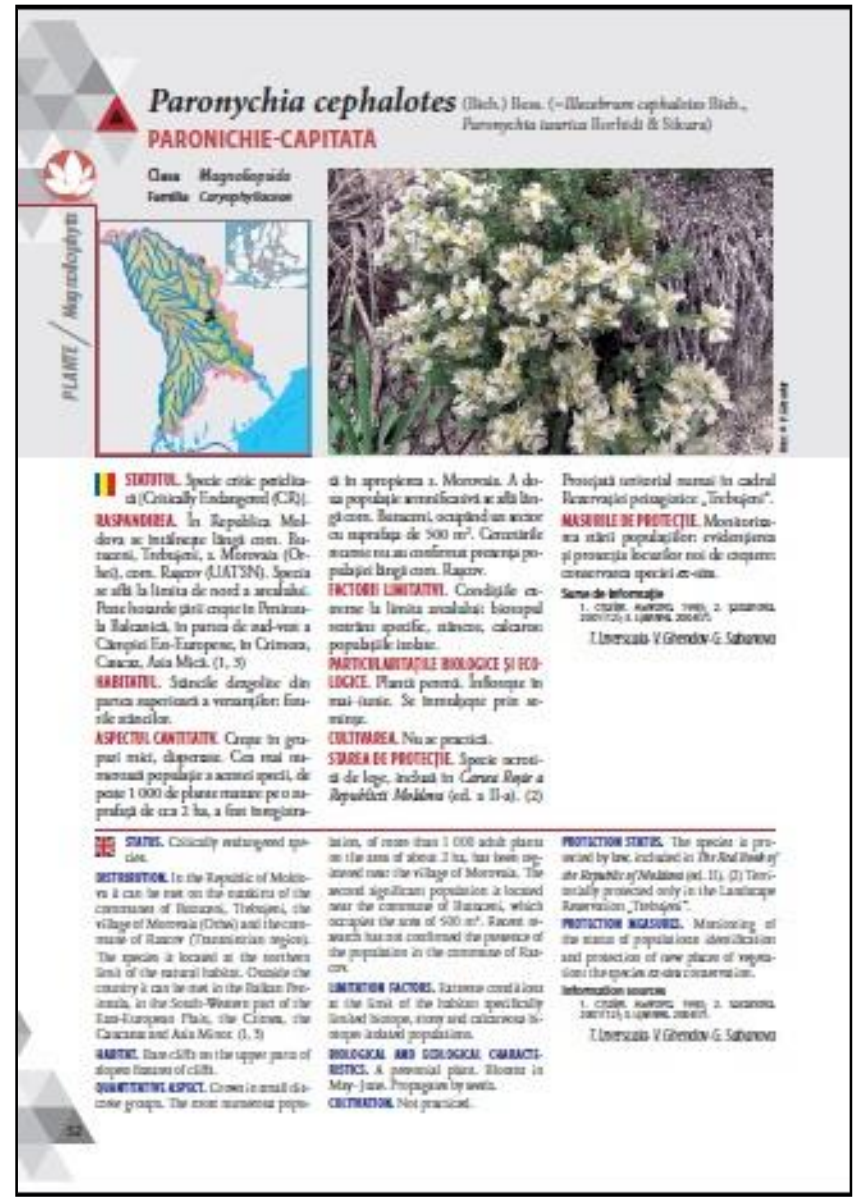

The species data of plants and fungi in the RBRM are similar to those in the Red Data Book of Ukraine (the RDBU), although given in a slightly different order: status (in the RDBU nature conservation status of species), distribution (habitat of species and its distribution in Ukraine), habitat (conditions of growing), quantitative aspect (quantity and structure of population), limitation factors (reasons of quantity changes), biological and ecological characteristics (general biomorphological feature), cultivation (multiplication and propagation under special conditions), separately represented protection status and protection measures (in the RDBU these subsections are united: regime of population conservation and protection measures), information sources (main sources of information). Unlike the RDBU, in the RBRM such important features of species, as its scientific and applied (ecosystem, economic, 
commercial) values, which are extremely important for understanding the value of the species by ordinary citizens are not indicated. The wordings of the names of fragments of species information presented in the RDBU in our opinion are more successful, because they reveal their content more precisely.

Of course, we consider it to be a positive point that the first name of the species is given in Latin, which, in accordance with the «International Code of Nomenclature of algae, fungi and plants» is the main, and the name in national language is given after it. Also the advantage of the book is a separate list of species of plants within the taxa of high rank. At the same time we consider that the systematics of taxonomic units, represented in the RBRM, is rather obsolete.

Of course, the advantage of the RBRM is the translation of materials into English, that makes the text more available to foreign users. But from other side the amount of information about each species is significantly reduced, which is a certain disadvantage. In our opinion the Red Book should concentrate detailed and regional, but not common information about biology, ecology structure of cenozes population of species, their reaction on unfavorable factors etc., because only detailed information can facilitate concrete actions on conservation of plants species.

In conclusion, we note again the fact that the lists of plants in the Red Books of Ukraine and Moldova have their differential peculiarities.

The disadvantages of the book include a limited amount of information about each plant, the use of only three sozological categories, and the use of obsolete nomenclature.

Among the positive aspects of the reviewed book it should be noted successful arrangements of taxonomic groups from organisms of higher rank to lower rank; availability of Latin (scientific) names of the species at first; the presence of the translation of taxa features into English.

Kolomiychuk V.P., Popova O.M. 